\title{
Influence of Demographic Variables on Immigrants Health Status
}

\author{
Md. Sayed Uddin \\ Sociology and Social Anthropology, Faculty of Social Sciences and Humanities, \\ Universiti Malaysia Sabah, Jalan UMS, 88400, Kota Kinabalu, Sabah, Malaysia \\ E-mail: sayed@ums.edu.my
}

Adam Andani Mohammed

Social Work Studies, Faculty of Social Sciences and Humanities, Universiti Malaysia Sarawak, Sarawak, Malaysia

E-mail: maandani@unimas.my

Received: April 29, 2020 Accepted: June 1, 2020 Online published: June 15, 2020

doi:10.5296/ijhrs.v10i3.17192 URL: https://doi.org/10.5296/ijhrs.v10i3.17192

\begin{abstract}
The aim of this empirical investigation is to assess Bangladeshi temporary migrant's general health status in Malaysia and factors affecting their health. The study was carried out through the quantitative method. A survey was conducted among 300 Bangladeshi migrant workers from construction, manufacturing and service sectors. The result indicates that the Bangladeshi temporary migrant workers reported positive self-reported health status with percentages good, very good and excellent. It was also found that the construction and service sector workers reported slightly better health status than manufacturing workers. Result showed that married workers have more health problems than singles. In addition, the low level of education creates more health problems among Bangladeshi workers. It was found that highly educated Bangladeshi workers are more likely to safeguard a sound health status. This study suggest considering Bangladeshi immigrants' health behaviours, health status and health needs, there should be early health promotion and necessary prevention and/or intervention to improve their health conditions.
\end{abstract}

Keywords: socio-demographic, health status, foreign workers, immigration, self-rated health 


\section{Introduction}

Health status and utilization of health services measures have been well studied in Western countries (Young, 2004). This may be due to the higher immigrant movement in those developed countries. Nevertheless, South-East Asian region is also being considered the most active migrant movement region. Malaysia is one of the top immigration countries with 2.4 million people that include migrant foreign workers, refugees, asylum-seekers and other groups of foreign nationals (Guinto et al., 2015: 8). Kanapathy (2006) mentions that contract migrant workers are about $22 \%$ of the Malaysian labour force, a relatively higher percentage compared to other East Asia countries that rely on imported labour. There are also expatriate professionals in this country; it is reported that only $3 \%$ of foreign workers have status as professional expatriates doing managerial, professional, and technical jobs (Kassim, 2005). Thus, the current study aims to investigate Bangladeshi temporary migrants' health status and its influential demographic factors. Studies found that socio-demographic variables influences health (Pol \& Thomas, 2001; Constant et al., 2018). Migrant health conditions have been influenced by various factors. This study will focuses on the relationship between migrant's health status and influential demographic factors such as age, marital status, education and duration of stay.

Malaysia is concerned about the health of migrant workers. It has allocated different schemes to ensure the health of migrant workers and established different centers that provide the necessary medical services to foreign workers Foreign Workers Medical Examination and Monitoring Agency (FOMEMA), (Kassim, 2005). It has also made provisions of medical checkup for migrant workers before they join the workforce. The employers are also instructed to take care of the health of the workers and bear the cost of medical treatment in case they suffer from ailments. The health issues of migrant workers and their access (or the lack of it) to health care services, particularly when they are vulnerable to work-related injuries thus occupy the dominant discourse among policymakers, academicians and researchers alike (Kanapathy, 2006; Abdul-Aziz, 2001). Health conditions of foreign workers in Malaysia and their limited access to health care services have attracted the attention of social scientists (Karim \& Diah, 2015; Kanapaty, 2006; Abubakar, 2002; Karim et al., 1999). Migrant workers in Singapore are also reported to have suffered from diseases like typhus, dengue and pneumonia due to the unhygienic and density in living conditions (cited in Lee et al., 2014). Indeed, previous studies have found that migrants are less healthy than destination population (Loue, 1998). Immigrants arriving in the host country are, on average, healthier than comparable natives and yet their health status dissipates with additional years in the country (Constant et al., 2018).

According to Karim and Diah (2015: 1), a large number of illegal workers are having difficulties and denied access medical facilities in Malaysia, putting their health status at risk. Such a scenario poses hazardous not only for them but also for the local people, their co-workers and others. As Karim et al. (1999: 68-69) note, the legal and illegal workers in Malaysia are sources to many social problems such as crime, job displacement, poor health, low standards and quality of life among others. This is further corroborated by the poor perception of foreign workers' arrival in Malaysia by the locals who often complain about the 
deteriorating quality of life having an adverse effect on health and hygiene (Karim et al., 1999: 94). It is worth mentioning that this influx of migrant workers in Malaysia raises serious implications on their health and their utilization of health centers such as hospitals and government clinics (Karim et al., 1999: 70). This research focuses on Bangladeshi temporary migrant workers' health status and influential affecting factors to their health status.

\section{Review of Literature}

Many studies have highlighted factors vis-à-vis immigrants' or migrants' health status. Studies demonstrate that individuals' health status have been influenced by socio-demographic, economic and non-economic factors. There is correlation between individuals' demographic profile and their health status (Pol \& Thomas, 2001). According to Pol and Thomas (2013: 3):

"Medical sociologists have been in the forefront of research on the extent to which demographic attributes such as income level and education affect health status and health behavior and a more expansive "sociology of health and healthcare" has emerged."

Pol and Thomas emphasized the impact and association of demographic attributes on health status and health behaviour. The demographic and other compositional attributes such as age, sex, race, income, education, marital status, religion, and socio-economic status are correlated with both health and health behaviour (Pol \& Thomas, 2013: 2).

Migrant health conditions and their utilization levels have been influenced by various factors. For instance, studies found that age (Krisnaswamy et al., 2009; Anton \& Bustillo, 2009) marital status (Young, 2004; Pol \& Thomas, 2001), higher education (Cho et al., 2013; Hoerster et al., 2010; Anton \& Bustillo, 2009), duration of stay (Constant et al., 2018) are influential factors for health. For instance, studies suggested that older individuals have more illness and more health care use (Young, 2004); marital status have all been found to be associated with health outcomes (Tuakli-Wosornu et al. 2014); Duration of stay influences health (Constant et al., 2018). However, in some instances, longer duration of stay has been found to be associated with practices such as utilization of preventive care that may enhance better health (Lebrun 2012).

As prior literature suggests, migrant workers' health deteriorates faster than that of the local population (Nguyen \& White, 2007; Jidong, 2008). For instance, Nguyen and White (2007), in their study on the health status of temporary migrants in Vietnam, found that temporary workers residing in guest houses have been seriously vulnerable in matters related to health issues. Although their self-reported health status indicates they are healthy, their health actually deteriorates faster than other groups in urban areas. As noted earlier, numerous studies of Bangladeshi migrants in Malaysia find them living in unhygienic accommodations and working in poor conditions, leaving the workers at risk as far as their health issues are concerned (Karim \& Diah, 2015; Abdul Aziz, 2001; Hill, 2012). Yet, very little has been studied to examine their health status and deterioration in their health conditions. 
A similar study conducted by Patel et al. (2012) deals with issues relating to Bangladeshi immigrants' health status, health behaviours, and access to health care in New York, United States. Health status was measured by using self-rated health status scale; 89 respondents reported their health as fair or in poor conditions. It is also found that immigrants' age had been associated with ailments such as hypertension and diabetics; mostly age significantly caused respondents to suffer from hypertension. As for health behaviour of Bangladeshi immigrants, they were found to be less engaged in physical activities, spending leisure time and exercising compared to other racial groups. According to the authors, Bangladeshi immigrants participated in limited physical activities which affected their health outcome.

Based on previous studies, this study established the following hypotheses, as follows:

\section{Hypotheses}

$\mathrm{H}_{1}$ The higher the age, the more the health problems

$\mathrm{H}_{2}$ Married workers have more health problems than singles

$\mathrm{H}_{3}$ The lower the education, the more the health problems

$\mathrm{H}_{4}$ Long duration of Bangladeshi workers' stay in Malaysia is positively related to their health status

\section{Research Methods}

The study was carried out through the quantitative method for the collection of the relevant data. This method is appropriate because it provides complete information of Bangladeshi migrant workers' health status and associated factors in the Malaysian context.

\section{Data Collection}

The study used the survey method based on face-to-face interview with Bangladeshi temporary contract migrant workers (non-professionals) in the construction, manufacturing and service sectors in Malaysia. Before the data collection process, the researcher followed a few steps to obtain the relevant data on Bangladeshi migrant workers' present health condition. The researcher collected a recommendation letter from the Head of Department, Sociology and Anthropology entitled "Permission to conduct research by $\mathrm{PhD}$ student" to facilitate access to respondents, relevant offices including the Bangladeshi High Commission and other organizations. This letter helped the researcher a lot during the data collection. Besides, the researcher was also engaged at Bangladesh High Commission in Malaysia during week days. The researcher asked questions and filled the answers by himself from participants. Each interview took about 50 minutes to complete.

\section{Population and Sample}

The population of this study comprised of male Bangladeshi temporary migrant workers in various sectors including construction, manufacturing and services sectors in Kuala Lumpur, (KL), Malaysia.

The present study adopted a two-stage sampling. Initially, Kuala Lumpur was divided into 
three clusters or units. Information had been gathered from the Bangladesh High Commission to select the major areas where large numbers of temporary Bangladeshi workers are found. The selected areas include Klang (Port Klang, North Port, West Port, Pangsapuri), the Centre of Kuala Lumpur (Gombak, the Bangladesh High Commission, Batu Caves), and around Kuala Lumpur (Nilai). Next, the population unit was divided into three clusters (construction, manufacturing and services) and from each cluster 100 respondents $(100+100+100)$ were selected through convenience random sampling procedure. The total number of respondents is 300 .

\section{Instrumentation and Operationalization of the Variables}

The instrument consisted of a survey of questions requesting demographic information and factors affecting migrants' health status and its affecting factors were used and prepared for data collection based on previous studies.

The operationalization of the variables considered for this study is presented below:

The respondents were asked several questions consisted of factors including age, marital status and educational attainment, duration of stay in Malaysia. Respondents' self-rated health status variable was dichotomized as good (excellent/very good/good) versus not good/well (fair/poor). Respondents' experience of any chronic illness was dichotomized as yes/no. In addition, respondents' sickness in the past one year was dichotomized as yes/no.

Health status: Health status was measured using two indicators (a) self-rated health status scale which was also used in previous studies by Pol and Thomass (2013), Andersen (1995), Patel et al. (2012) and (b) sickness in one year which was also used in previous studies by Hesketh et al. (2008). Self-rated health status question have five categories as answers: 'excellent,' 'very good,' 'good,' 'fair,' and 'poor.' They were coded as good (excellent, very good, good,) and not good (fair, and poor). Respondents 'experience of ailments (sickness) in the past 12 months was coded as yes/no.

\section{Data Analysis}

Data were coded and recoded through Statistical Package for the Social Sciences (SPSS) version IBM22. Data were analyzed using frequency distribution and the binary logistic regression, to find out the association between variables and compare the strong predictors affecting health status of temporary Bangladeshi workers in Malaysia.

\section{Results and Discussions}

\section{Length of Stay in Malaysia}

Duration of stay has an impact on the health status of migrant worker (Akresh, 2009). In a study, Constant et al. (2018) found that the number of years a migrant has lived in James Town is a predictor of self-rated health status. Migrants who have lived longer in James Town are more likely to have better rating on their health status than migrants with relatively shorter duration of stay at the destination. On the contrary, a study shown that longer duration of stay is associated with individual level practices like access to and utilization of health care 


\section{Macrothink}

service, especially preventive care, which may enhance better health (Lebrun 2012). Figure1 indicates that the majority of respondents $(54.7 \%, \mathrm{n}=164)$ have been working in Malaysia for 7 to 8 years. It is followed by $44.7 \%$ who have been working for $9-10$ years. Only .7\% of them working have been in this country for 3-4 years. The results show that Bangladeshi migrant workers are staying in Malaysia for long duration of period because in 2007 and 2008 huge migration of such workers to Malaysia took place (Ullah, 2011: 91-109).

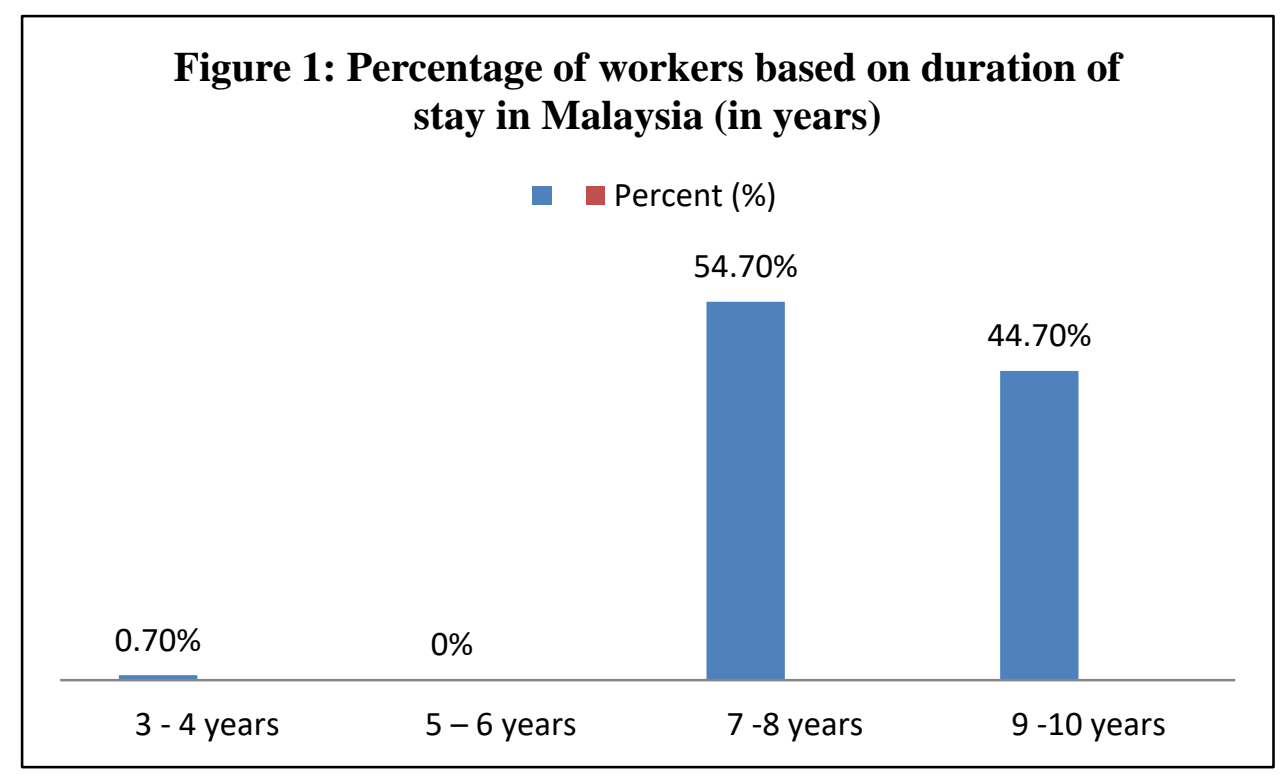

\section{Workers' Health Condition (Sector Wise):}

Workers' health conditions were assessed using self-rated health status in the last 12 months and felt sickness in the last 12 months. We also compared the workers' sickness according to sectors, as a majority Bangladeshi temporary contract migrant worker is working major three sectors such as: Construction sector, manufacturing sector and service sector. The results as follows:

\section{Self-Reported Health Status (Last 12 Months)}

Self-reported health status measure scale is one of the tools used in several studies to assess individual health status. Considering all 300 samples, the majority of the workers $(63.3 \%)$ reported that their overall health status is good, $18.7 \%$ of them reported that their health is fair. Further, $12.7 \%$ considered their health very good and $4 \%$ considered their health excellent. Only $1.3 \%$ claimed that their health status is poor. Figure 2 shows comparison of the respondents' according to sector. The majority of construction workers $(67 \%)$ stated that their health status is good compared to the workers of other sectors. 


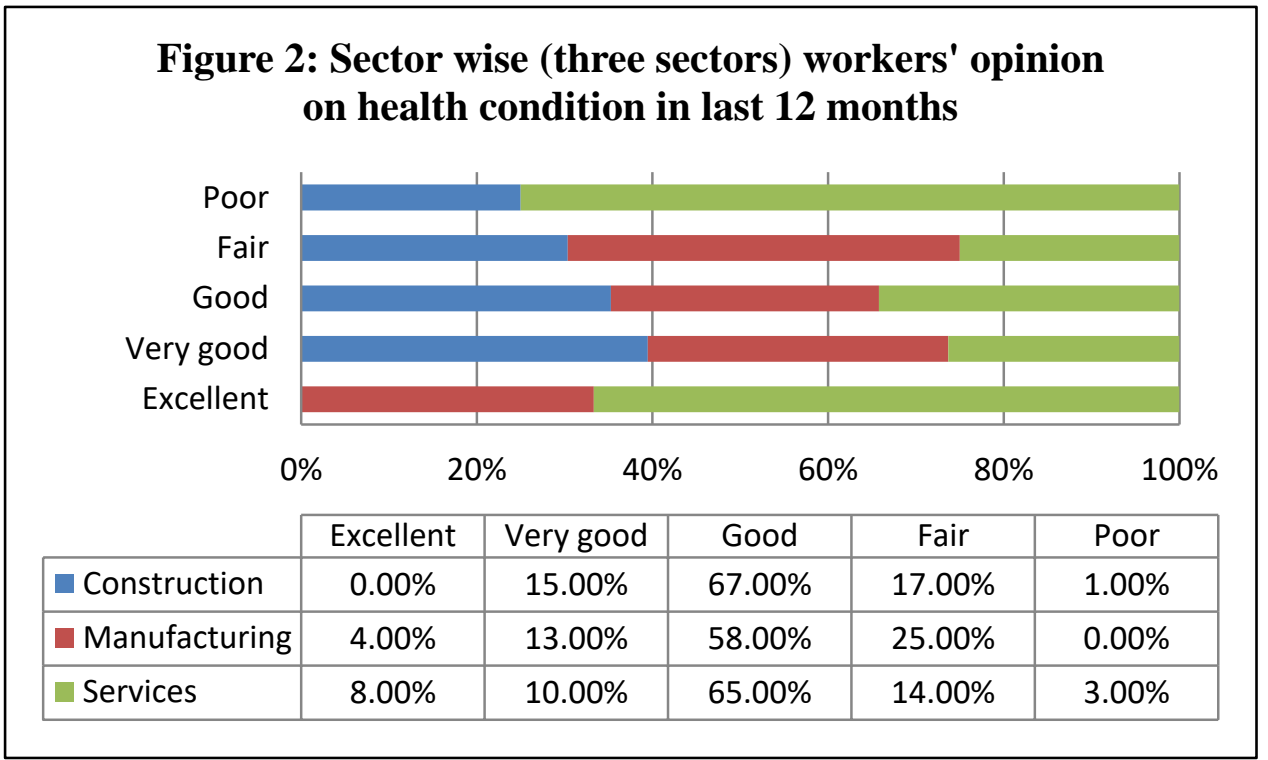

Felt Sickness Last 12 Months (sickness report)

The study inquires how many respondents fell sick in the last 12 months. The data reveal that the majority $(\mathrm{n}=212 ; 70.7 \%)$ of the Bangladeshi workers from all three sectors have been sick in the last 12 months. Only $29.3 \%$ of the workers did not fall sick during this duration. Figure 3 indicates that $81 \%$ of the construction workers fell sick during the last one year while $66 \%$ percent of service workers and $65 \%$ of manufacturing workers fell sick during the same period.

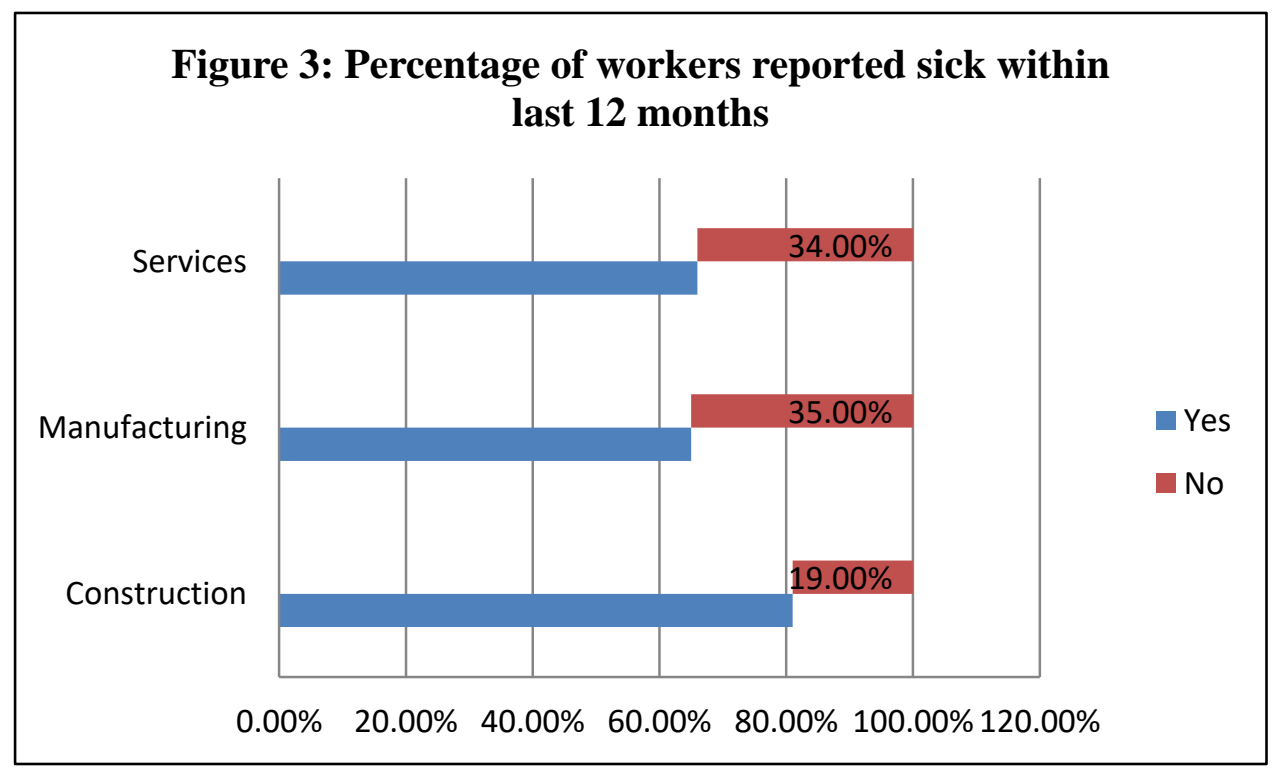

\section{Types of Illness}

Figure 4 showed that the majority of Bangladeshi migrant workers (26.3\%) suffer from gastritis, $13.3 \%$ of them suffer from migraine and headaches, and $7 \%$ suffer from diabetes. Against this, $24.3 \%$ of the respondents have no health problems and $21.7 \%$ have health problems of other nature. 
Figure 4: Percentage of respondents reports on types of illness reported $(\%)$

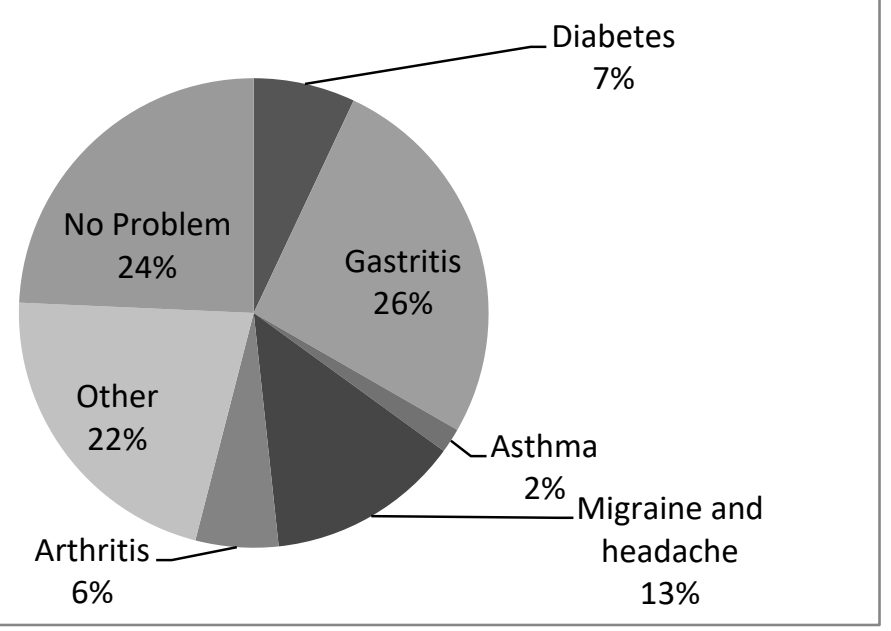

\section{Influential predictors on health status:}

The study applies logistic regression model to show the probability level of Bangladeshi workers' health status from the influence of certain independent variables. These are workers' age, marital status, educational attainment and duration of stay in Malaysia. Table 1 showed that in the case of self-rated health status, two variables with the exception of age and years in Malaysia and for sickness within the past 12 months, all four variables are found significant at $5 \%$ level.

First age is significant and negatively related to workers' health status for sickness in the past 12 months. It implies that the older workers were less likely associated with sickness in the previous one year. Thus, the first hypothesis H1 (The higher the age, the more the health problems) is not supported. It may be due to the fact that the older workers earn higher monthly salary and maintain a sound health by eating rich food for their health; this is consistent with other studies (Abou-Taleb et al., 1995). It may also be possible because the involvement of older workers in the construction and manufacturing sectors is less. Various research are consistent with this finding that young Bangladeshi workers are more involved in construction sector and as such, they are more at risk (Abdul Aziz, 2001). This finding contradicts with Young's (2004). For instance, older individuals have more illness and more health care use (Young, 2004). Another study by Patel et al. (2012) found that immigrants' age is associated with hypertension and diabetics.

Second, marital status is significant and negatively related to the self-reported health and sickness in the past 12 months. It implies that married workers' were less likely to maintain a sound and good health status. Further, being married was associated with high level of illness in the previous one year. It may be because married workers have the tendency to earn a handsome salary even working in hazardous conditions and doing huge overtime to support their families at home, sending the maximum amount of remittances rather than maintain health. From the present findings it is suggested that hypothesis H2 (Married workers have more health problems than singles) is supported. This result contradicts with other findings. 


\section{Mll Macrothink}

In general, persons who are married have better health status than those in other categories (Young, 2004). Married persons feel better, function better and have less illness, less serious illness, better illness outcomes and less mortality (Pol \& Thomas, 2001).

Third, education is significant and positively related to the workers' good health status for the self-reported health scale. The result implies that the higher educated workers are more likely to maintain a sound and good health status during their stay in Malaysia. It may be because less educated workers are involved in hazardous working conditions and have less opportunity to maintain good health status compared to higher educated migrant workers. Education also affects health in various ways, for example, its association with self-awareness of diseases and illness, knowledge concerning non-favourable behaviours like smoking and drinking, and use of modern health services. Regression result also shows that education is significant and negatively related to sickness in the past 12 months. It implies that Bangladeshi workers who obtained higher education were less likely to report sickness in the past 12 months. Thus, the result of the regression supports H3 (The lower the education, the more the health problems). This finding is consistent with other study Gilmore et al., (2001). Gilmore et al. (2001) found that lack of education had a negative impact on health in both males and females.

Finally, duration of stay in Malaysia is significant and positively associated to health status for sickness in the past 12 months. This indicates that the longer the workers stay in Malaysia they were more likely to reported being sick or ill. This also indicates that the longer the stay in Malaysia, health deteriorates faster among Bangladeshi workers than other short term workers. Thus, leads to the conclusion that hypothesis H4 (Long duration of Bangladeshi workers' stay in Malaysia is positively related to their health status) is not-supported.

Table 1. Logistic regression model for factors influencing health status

\begin{tabular}{lrrr}
\hline Sickness in past 12 months & & & \\
\hline Variables & B & S.E. & Sig. \\
\hline Self-rated health status & & & \\
$\quad$ Age & -.042 & .210 & .843 \\
$\quad$ Marital & -.980 & .414 & $.018^{* *}$ \\
$\quad$ Education & .477 & .200 & $.017^{* *}$ \\
$\quad$ Years in Malaysia & -.118 & .298 & .693 \\
Sickness in past 12 months & & & $.001^{* * *}$ \\
$\quad$ Age & -.564 & .176 & $.000^{* * *}$ \\
$\quad$ Marital & -1.567 & .375 & $.009^{* * *}$ \\
$\quad$ Education & -.440 & .169 & $.022^{* *}$ \\
$\quad$ Years in Malaysia & .601 & .263 & \\
\end{tabular}

Note: *,** and $* * *$ significant at 10,5 and 1 percent, respectively. 


\section{Conclusion}

The present study explores Bangladeshi workers' present health status in Malaysia. We have found that overall, their health status is good. This is because they have provided a positive self-reported health status with percentages (63\%) good, (12.7\%) very good and (4\%) excellent. It was also found that the construction and service sector workers reported slightly higher health status than manufacturing workers. This may be because of the long working hours of manufacturing workers and their physical involvement in job. The majority of respondents reported sickness in one year $(70.7 \%)$. The types of medical illness they faces while working in Malaysia are diabetes, gastric disease, asthma, migraine and headaches, arthritis, dengue fever and other problems. The results also explore the affecting factors associated with the health status of Bangladeshi migrant workers in Malaysia. As discussed earlier, the health status was measured using two indicators (a) self-rated health status scale and (b) reported sickness in one year. Our hypothesis confirms that married workers have more health problems than singles. Being married is less likely to report better health status than those who are not. In addition, the low level of education creates more health problems among Bangladeshi workers. It was found that that higher educated Bangladeshi worker are more likely to safeguard a sound health and report better self-rated health status. This study suggest considering Bangladeshi immigrants' health behaviours, health status and health needs, there should be early health promotion and necessary prevention and/or intervention to improve their health conditions. Because poor health adversely affects productivity and the opportunity to develop sustainable economies.

\section{References}

Abdul-Aziz, A. R. (2001a). Bangladeshi migrant workers in construction sector. Asia-Pacific Population Journal, 16(1), 3-22. https://doi.org/10.18356/e085943a-en

Abou-Taleb, A. N., Musaiger, A. O., \& Abdelmoneim, R. B. (1995). Health status of cement workers in the United Arab Emirates. Journal of the Royal Society of Health, 115(6), 378-381. https://doi.org/10.1177/146642409511500610

Abubakar, S. Y. (2002). Migrant labour in Malaysia: Impact and implications of the Asian financial crisis. EADN regional project on the social impact of the Asian financial crisis. http://www.eadn.org/Migrant\%20Labour\%20in\%20Malaysia\%20Impact\%20and\%20Implicat ions $\% 20$ of\%20the.pdf

Abubakari, A. R., \& Bhopal, R. S. (2008). Systematic review on the prevalence of diabetes, overweight/obesity and physical inactivity in Ghanaians and Nigerians. Public Health, 122(2), 173-182. https://doi.org/10.1016/j.puhe.2007.06.012

Akresh, I. R. (2009). Health service utilization among immigrants to the United States. $\begin{array}{lllll}\text { Population Research } & \text { Rolicy }\end{array}$ https://doi.org/10.1007/s11113-009-9129-6

Andersen, R. (1995) Revisiting the Behavioral Model and Access to Medical Care: Does It Matter? Journal of Health and social behavior, 36, 1-10. https://doi.org/10.2307/2137284 
Anton, J. I., \& Bustillo, R. M. (2009). Health care utilisation and immigration in Spain. Eur J Health Econ, 11, 487-498. https://doi.org/10.1007/s10198-009-0204-z

Cho, N., Yew, C. K., Cheah, H. Y., Ng, S. Y., Loh, M. Y., Lim, X. J., Wong, C. K., Sivasanggari, A/P S. (2013). Knowledge of medication use and factors influencing the utilization of public health clinics, Int Health, 5, 217-222. https://doi.org/10.1093/inthealth/iht019

Constant, A. F., García-Muñoz, T., Neuman, S., \& Neuman, T. (2018). A "healthy immigrant effect" or a "sick immigrant effect"? Selection and policies matter. The European Journal of Health Economics, 19(1), 103-121. https://doi.org/10.1007/s10198-017-0870-1

Gilmore, A. B., McKee, M., \& Rose, R. (2002). Determinants of and inequalities in self-perceived health in Ukraine. Social science \& medicine, 55(12), 2177-2188. https://doi.org/10.1016/S0277-9536(01)00361-6

Guinto, R. L. L. R., Curran, U. Z., Suphanchaimat, R., \& Pocock, N. S. (2015). Universal health coverage in 'One ASEAN': are migrants included?. Global health action, 8(1), 25749. https://doi.org/10.3402/gha.v8.25749

Hesketh, T., Jun, Y. X., Lu, L., \& Mei, W. H. (2008). Health status and access to health care of migrant workers in China. Public health reports, 123(2), 189-197. https://doi.org/10.1177/003335490812300211

Hoerster, K. D., Beddawi, S., Peddecord, K. M., \& Ayala, G. X. (2010). Healthcare Use Among California Farmworkers: Predisposing and Enabling Factors. J Immigrant Minority Health, 12, 506-512. https://doi.org/10.1007/s10903-009-9305-0

Kanapathy, V. (2006, December). Migrant workers in Malaysia: an overview. In Country paper prepared for Workshop on East Asian Cooperation Framework for Migrant Labour, Kuala Lumpur. http://www. isis. org. my/files/pubs/papers/V K_MIGRATION-NEAT_6Dec06.pdf

Karim, A. Z., \& Diah, N. M. (2015). Health seeking behavior of the Bangladeshi migrant workers in Malaysia: Some suggestive recommendations in adjustive context. Asian Social Science, 11(10), 348. https://doi.org/10.5539/ass.v11n10p348

Karim, A. H. M., Zehadul, A. M., \& Isa, M. (1999). Foreign workers in Malaysia: Issues and implications. Kuala Lumpur: Utusan Publications \& Distributiors Sdn. Bhd.

Kassim, A. (2005). Security and social implications of cross-national migration in Malaysia. Mohamed J.H. Pacifying the Pacific: Confronting The Challenges (259-288); ISIS Malaysia: Kuala Lumpur.

Krishnaswamy, S., Kavitha, S., Wah, Y. L., Jemain, A. A., Tishya, I., Padma, K. R., ... Vikram, P. (2009). Contributing to Utilization of Health CareServices in Malaysia: A Population-Based Study. Asia-Pacific Journal of Public Health, 21(4), 442-450. https://doi.org/10.1177/1010539509345862 
Lebrun, L. A. (2012). Effects of length of stay and language proficiency on health care experiences among immigrants in Canada and the United States. Social Science and Medicine, 74(7), 1062-1072. https://doi.org/10.1016/j.socscimed.2011.11.031

Lee, W., Andy, N., Sandra, T., Alex, R. C., Mee, L. W., Joshua, T., ... Chwin H. (2014). Health-seeking behaviour of male foreign migrant workers living in a dormitory in Singapore. BMC health services research, 14(1), 300. https://doi.org/10.1186/1472-6963-14-300

Loue, S. (ed.) (1998). Handbook of Immigrant Health. Plenum Press. https://doi.org/10.1007/978-1-4899-1936-6

Nguyen, L. T., \& White, M. J. (2007). Health Status of Temporary Migrants in Urban Areas in Vietnam1. International Migration, 45(4), 101-134. https://doi.org/10.1111/j.1468-2435.2007.00421.x

Patel, V. V., Rajpathak, S., \& Karasz, A. (2012). Bangladeshi immigrants in New York City: a community based health needs assessment of a hard to reach population. Journal of immigrant and minority health, 14(5), 767-773. https://doi.org/10.1007/s10903-011-9555-5

Pol, L. G., \& Thomas, R. K. (2001). The demography of health and health care. Springer Science \& Business Media.

Pol, L. G., \& Thomas, R. K. (2013). Health Demography and Public Policy. In The Demography of Health and Healthcare (pp. 275-294). Springer, Dordrecht. https://doi.org/10.1007/978-90-481-8903-8_12

Tuakli-Wosornu, Y. A., Rowan, M., \& Gittelsohn, J. (2014). Perceptions of physical activity, activity preferences and health among a group of adult women in urban Ghana: A pilot study. Ghana Medical Journal, 48(1), 3-13. https://doi.org/10.4314/gmj.v48i1.1

Ullah AKM A. (2011). Integrative rhetoric and exclusionary realities in Bangladdesh-Malaysia migration policies: discourse on networks and developments. In Wong Tai-Chee, Rigg J. (eds.) (2011), Asian Cities, Migrant Labor and Contested Spaces (pp.91-109). Routledge: New York.

Young, J. T. (2004). Health in the developing world: Health status and healthcare utilization in Matlab, Bangladesh. University of Colorado at Boulder. ProQuest Dissertations Publishing, 3153893.

\section{Copyright Disclaimer}

Copyright for this article is retained by the author(s), with first publication rights granted to the journal.

This is an open-access article distributed under the terms and conditions of the Creative Commons Attribution license (http://creativecommons.org/licenses/by/4.0/). 